\title{
EL PENSAMIENTOVESTIDO DE LOCO. ESCRITURA E INSPIRACIÓN EN LA OBRA DE CALDERÓN ${ }^{1}$
}

\author{
Wolfram Aichinger \\ Institut für Romanistik \\ Univ. Wien \\ Campus AAKH \\ Garnisongasse 13/ Hof 8 \\ 1090 Wien (Österreich)
}

En un estudio elemental, La imaginación en el metateatro calderoniano, Bruce Wardropper señaló el nexo entre la imaginación, el sueño y la creatividad poética - tanto del dramaturgo como de sus personajes en juego $^{2}$. Partiendo de sus sabias consideraciones, intentaré trazar brevemente la relación entre el acto de escribir y los misteriosos fondos del alma donde nace la inspiración y arranca la invención dramática. No volveré a tratar las bases filosóficas y poéticas y el contexto barroco de Calderón. Para ello remito a la obra del autor que acabo de mencionar. Mi propósito es más modesto: dar a conocer y conectar pasajes de obras menos conocidas que dan fe de la continua atención del poeta Calderón

1 Este breve estudio es parte del proyecto «Geheimnisse und Geheimhaltung in Calderóns Komödien und im Habsburg-Spanien; mit einer kritischen Ausgabe von El secreto a voces (Das laute Geheimnis) von Don Pedro Calderón de la Barca», subvencionado por el Wissenschaftsfonds FWF, P 24903-G23 y el Jubiläumsfonds der ÖNB, 14725. Quiero expresar mi gratitud hacia Paula Casariego, Carmen Hasenknopf, Simon Kroll, Fernando Rodríguez-Gallego, Alicia Vara López, Adrián J. Sáez, Rocío del Pilar Flórez Rodríguez, Marilyn Vargas y Michael Delgado.

${ }^{2}$ Wardropper, 1968, pp. 923-930. 
hacia los temas de la escritura, de la gestación psicológica de las imágenes y de la fuerza de las visiones del alma. Asignaré amplio espacio a las citas de obras calderonianas porque creo que solo siguiendo el hilo de sus razonamientos literarios verso por verso quedan patentes la modernidad de su poética y la profundidad de sus reflexiones poetológicas. Con esto, tal vez pueda demostrar que una aproximación psicoanalítica sí puede compaginarse con un lose reading de Calderón y de este modo contribuir a una revaloración de enfoques psicológicos ${ }^{3}$, presentes en la crítica norteamericana pero un tanto arrinconados en España.

\section{BORRADORES Y BORRONES}

Empezaré con una cuestión que remite al tema general de esta publicación: ¿Se han conservado papeles que podríamos calificar de borradores? ¿papeles que serían testimonio del momento en que el poeta se halla en trance de querer expresar algo, algo que todavía busca su forma adecuada? ¿documentos que reflejen al autor en trance de inventar y combinar temas, motivos, imágenes, escogiendo o rechazando ideas, ex-
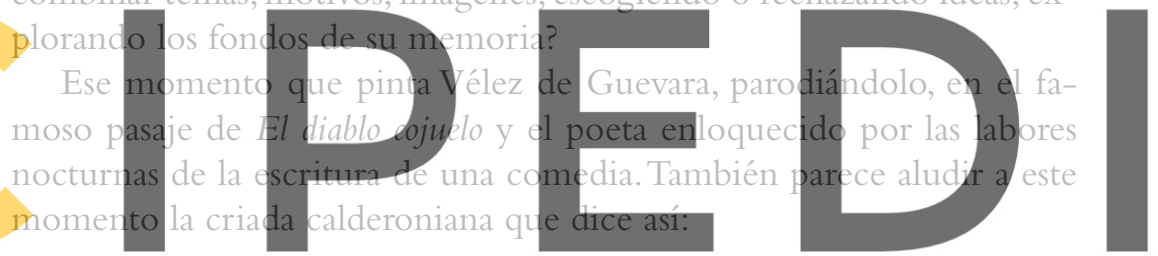

INÉS Leyendo mi ama un papel,

free at https//www.scipediaiconotomdownload the version without the wa

que mil deseos me da

de saber lo que hay en él,

Una vez le aja furiosa, y al cielo elevada mira, otra llora, otra suspira.

$[\ldots]$

A leer vuelve. ¿De qué nace ya el agrado y ya el furor?

${ }^{3}$ Así, Frederick A. de Armas, 2014,p. 110, indica el nexo entre el cielo y las estrellas que conforman una escritura secreta por una parte y el diseño del alma humana por la otra: «Since man was considered to be a microcosm, heavenly writings could be mirrored in that inner chart that surfaces as a sueño". 
Sin duda que es borrador

de alguna comedia que hace ${ }^{4}$.

Todo indica que Calderón solía descartar muchos borradores hasta quedarse satisfecho con la versión que al final sacaba en limpio ${ }^{5}$. Entonces no podemos suponer que el autógrafo calderoniano refleje todas las fases de un proceso creativo, desde la inventio, pasando por la dispositio hasta la elocutio. El autógrafo, pongamos de la comedia El secreto a voces, es un artefacto en que el poeta se refleja como 'copista de sí mismo' preparando una versión presentable y vendible —a base de textos que preceden al autógrafo que conservamos en el proceso de escritura y reescritura. Sin embargo, esta versión limpia también contiene tachaduras, palabras sustituidas por otras, versos borrados, papeles pegados encima de una versión descartada. Estas intervenciones son de gran interés porque significan algo así como un regreso al borrador, a fases del proceso creativo que ya se dieron por superadas.

Los borrones siempre nos enfrentan con un porqué. ¿Por qué se

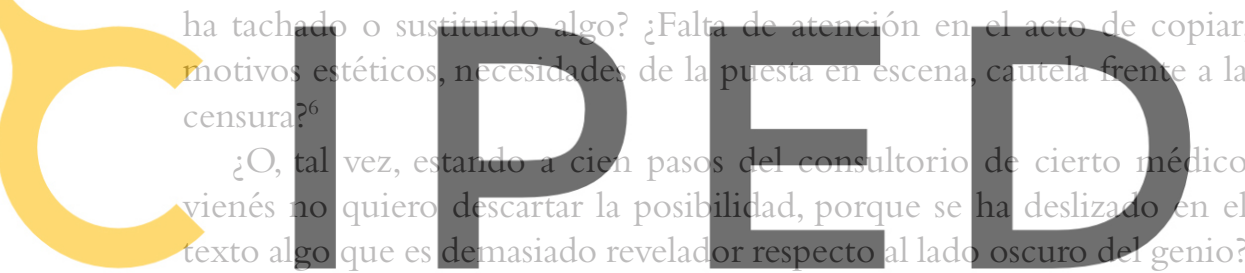

Debatimos en nuestro grupo de investigación la curiosa diferencia free at https//WhW.Scipedia.com to download the version without the wa dtras que mediante vigoroso giro de la pluma ocultan la palabra o el verso corregido debajo de una gruesa capa de tinta y unos signos que significan que aquello ya no significa.

Un borrón tiene la fuerza de atracción propia de todo objeto tapado, cubierto, velado, escondido. Ejerce la fascinación del secreto. Despierta la curiosidad de aquel «que halla en un libro / borradas algunas letras, /

${ }^{4}$ Calderón, No siempre lo peor es cierto, pp. 1458-1459.

5 «FLor.- Imagino / que haces alguna comedia, / y vas, de miedo del silbo, / descartando borradores», Calderón, Para vencer amor, querer vencerle, p. 551.

${ }^{6}$ Recordemos de paso, sin entrar en el tema, que a Calderón le preocupaba más la corrección de los autos sacramentales porque por un desliz de la pluma se hubiera podido introducir en el texto algo que estuviera reñido con la fe católica (Calderón, Prólogo que don Pedro Calderón hizo cuando imprimió el primer tomo de sus autos, p. 41). 
que, por sólo estar borradas, / le da más gana de leerlas» ${ }^{7}$, diría Calderón o más bien la dama Marcela en Casa con dos puertas mala es de guardar.

2. «¿YO OS HE DICHO QUE ESCRIBÁIS DESTA SUERTE?»

En el mundo dramático creado por Calderón, muchas veces se recurre a la simbología y fuerza expresiva del papel, de la tinta, de la letra y la escritura. El acto de escribir se sitúa entre dos extremos. Por un lado están los personajes que intentan escribir pero no pueden porque se le atropellan los pensamientos. Fracasa la escritura de, por ejemplo, una carta debido a que la mente, hallándose asaltada por fuertes afectos, no sabe organizar el material que se le presenta de manera caótica.

ELVIRA

ANA

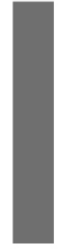

¿Acabaste de escribir?

Escribí, mas no acabé,

que antes pienso que empecé

en cada letra a sentir:

quise en una breve suma

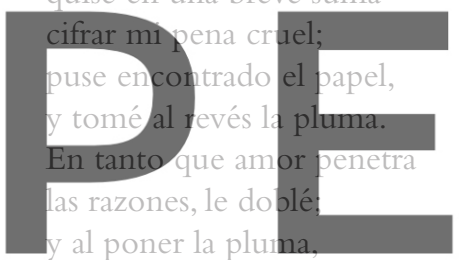

fue un borrón la primera letra.
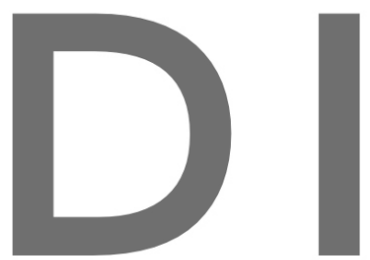

free at https//www.scipedia com com dión ownload the version without the wa

que mal puedo el mal que siento

decirie, si no en borrón.

Confusa y dudosa estaba

que principio tomaría;

y aunque muchos prevenía, ninguno me contentaba.

¿No has visto en una redoma

subir el agua con pena

menos, cuando está más llena

hasta que algún viento toma?

Así fui, porque al sentir,

tantas cosas concurrieron,

${ }^{7}$ Calderón, Casa con dos puertas mala es de guardar, p. 146. 
que unas a otras sirvieron

de estorbo para salir ${ }^{8}$.

Por otro lado tenemos a escribientes que pierden el dominio sobre aquello que mano, tinta y pluma articulan en el papel. Veamos de nuevo la comedia temprana Nadie fíe su secreto. El momento que nos interesa está en la Tercera Jornada. La relación triangular entre un duque, Alejandro Farnesio, su secretario y privado, César, y la dama, Ana de Castelví, está a punto de dar un vuelco decisivo. El duque dicta una carta en la cual dispone el matrimonio de Ana y obliga a escribir la carta siguiendo su dictado a la persona menos indicada:
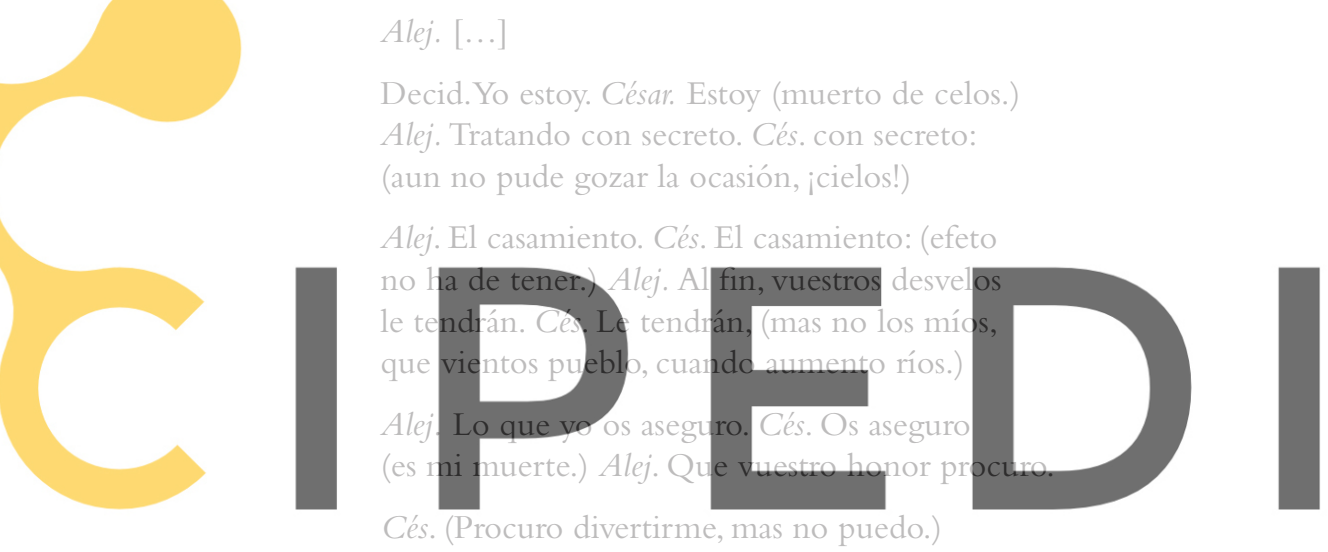

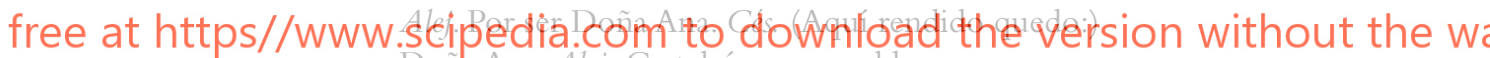
Dona Ana. Alej. Castelví por su nobleza.

y ángel por sus virtudes, y belleza.

Cés. ¿Dónde tu Alteza aquesta carta envía?

Alej.A Flandes. Cés. Para Flandes no es hoy día, y así, podrá dejarse hasta mañana.

Alej. (Perdió el color al nombre de Doña Ana:)

no importa que hoy no sea,

escrita se estará. Cés. (¿Quien hay que crea

tan tirano rigor, pena tan fiera?)

Alej. Proseguid, repitiendo la postrera razón. Cés. Rendido quedo.

${ }^{8}$ Calderón, Nadie fíe su secreto, en Comedias. Novena parte de comedias, p. 177. 
Alej. Pues yo he dicho ${ }^{9}$

tal razón? Dad acá. Cés. (Lo dicho he dicho;)

Toma la carta Alejandro y lee. xxx Silva!!!

Alej.Yo estoy muerto de celos, tratando con secreto, aun no pude gozar la ocasión, el casamiento efecto no ha de tener, al fin vuestros desvelos le tendrán, no los míos; lo que yo os aseguro, es mi muerte, que vuestro honor procuro, por ser Doña Ana: aquí rendido quedo.

¿Yo os he dicho que escribáis desta suerte? ${ }^{10}$

Citamos de la edición facsímil basada en Vera Tassis, 1691 y mantenemos la disposición gráfica ya que es guía imprescindible para una recitación que se acerque al espíritu del siglo XVII. Para el editor era importante marcar la tensión entre la forma métrica (la silva) que une

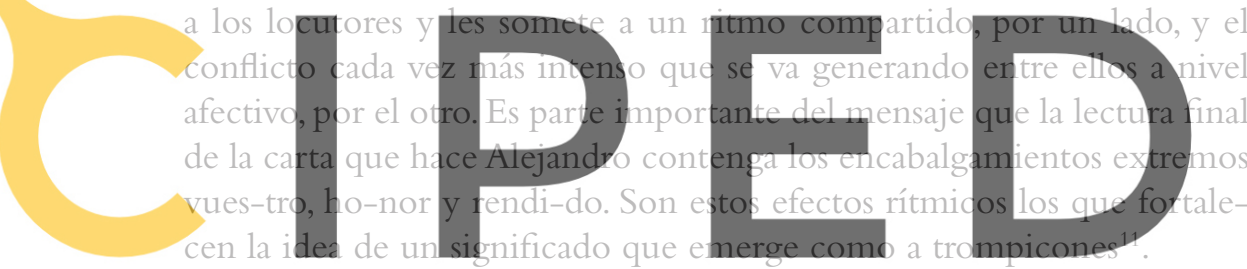

Los versos citados son un ejemplo entre tantos en que Calderón des-

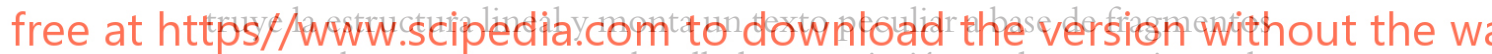
en que chocan y entran en batalla la enunciación y el pensamiento, la voluntad propia y la ajena ${ }^{12}$, el diálogo y el aparte, la realidad y el deseo,

${ }^{9}$ Curiosamente, Vera produce aquí un verso hipométrico de cuatro sílabas «pues yo he dicho", imposible en una silva, y que debería ser el segundo hemistiquio del heptasílabo anterior que empieza por «razón Ces. Rendido quedo». De esta manera no quedaría ningún verso suelto y ninguno hipométrico.

${ }^{10}$ Calderón, Nadie fie su secreto en Comedias. Novena parte de comedias, p. 194.

${ }^{11}$ La edición de Valbuena Briones cambia de renglón en cada cambio de locutor, de este modo apenas se puede reconocer el metro (Calderón, Nadie fie su secreto en Obras completas. Comedias, pp. 122-123). Sería interesante un rastreo del motivo en los contemporáneos de Calderón. Encontramos un paso parecido en Quien habló, pagó (pp. 248-251), atribuida a Tirso de Molina.

${ }^{12}$ Margarita, personaje calderoniano lo expresa así: «MARG.- ¿No has visto, / cuando uno habla y otro escribe, / al que escribe, con el ruido / de las voces, dar al pliego / 
el pasado, presente y futuro, lo intencionado y lo fortuito, el yo consciente y sus sombras, la contención del secreto y el desbordamiento de la confesión ${ }^{13}$.

El acto de escribir está cargado de fuertes afectos, de tal modo que puede llegar a sustraerse al control del yo, incluso puede desencadenar la revelación involuntaria de secretos. Enfrenta al que escribe con sus propias pasiones y los niveles escondidos de su personalidad. No difiere este acto de escribir de otros procesos de creación. Ello se da en La estatua de Prometeo donde el protagonista solo consigue liberarse de una imagen nocturna de la diosa Minerva al convertirla en escultura, sacándola de la oscuridad y transfiriéndola a la luz del día ${ }^{14}$ :

PROMETEO

di en aprehender su hermosura [de Minerva] tan viva en mi fantasía

que no había parte alguna

en que no me pareciese

mirarla, con tan aguda

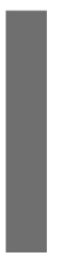

vehemencia que aun en las sombras
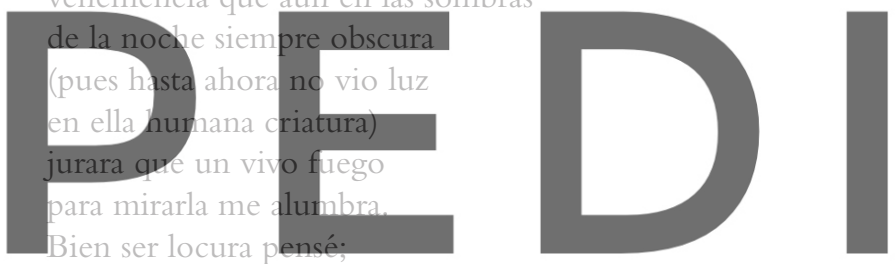

pero como a locura

free at https//www.scipedia.com toparanload the version without the wa
cierto genero de cura,
complacer quise la mía,
siguiendo su tema en una
estatua que me dictaba
el arte de la escultura,
creyendo que con tenerla
siempre a la vista segura,

lo que oyó, y no lo que quiso? / Pues así, escuchando yo / no sé que callados gritos / que me da el alma acá dentro, / conceptos formo distintos / de suerte que equivocada, / no me agrado del estilo, / porque escribo lo que oigo, / y no lo que quiero escribo" Calderón, Para vencer amor, querer vencerle en Obras completas. Comedias, p. 551.

${ }^{13}$ Vara López, 2014, p. 83.

${ }^{14}$ Ver al respecto Iglesias Feijoo y Vara López, 2013. 
cesaría el verla en sombras

de fantásticas figuras ${ }^{15}$.

\section{El asalto DE LAS IMÁGENES}

Hablar del acto de la escritura sin interesarse por las esferas de la mente de donde surge la inspiración es como pensar que un árbol acaba donde toca la tierra, valga la imagen de una parábola de Kafka.Voy a alejarme un momento del tema principal y proponer lo siguiente: Donde mejor se perfila el paso de la inspiración a la expresión es en aquellos dramas que tratan de sueños, alucinaciones y visiones ${ }^{16}$. Son muchos, no hace falta remitirse a Segismundo, Basilio y Clorilene. La obra intitulada La gran Cenobia se abre con las palabras agitadísimas de un personaje que despierta y no logra deshacerse de la imagen del sueño, la figura ensangrentada de su padre ${ }^{17}$. La cisma de Inglaterra también se inicia en el territorio onírico. Enrique, rey de Inglaterra, sueña que escribe y que una mujer (Ana Bolena) borra las líneas que él ha dejado sobre el papel ${ }^{18}$.

O veamos el drama El purgatorio de San Patricio. Ofrece toda una serie de sueños visionarios, apariciones fantásticas y diabólicas. On gran
númerd de versos, metáfor ds y casos de oxímoron transniten el darâcter,
así como 1 limpacto fisiológico y afectivo de estas visiones. Dejemos de
lado el debate teológico sobre el valor de estas visiones y, asumiendo el
riesgo del anacronismo, intentemo discernir algunas características de
los sueños calderonianos. Su parecido con las teorías de la psicología

puesto a imágenes que lo inundan, espantan, atormentan. La imagen nocturna es generada por fuerzas ajeñas al control del soñador. Lo dice Egerio, rey de Irlanda, al comienzo de la obra mencionada:

Polonia Durmiendo estabas. Di, señor, ¿qué tienes?

Egerio Todo el tormento eterno de las sedientas furias del infierno, partos de aquella fiera

15 Calderón, La estatua de Prometeo, pp. 245-246; Greer, 1986, pp. 117 y 121-132; Egido, 1989, pp. 49-50; López López Pielow, 2010, pp. 215-217.

${ }^{16}$ Ver al respecto Valbuena Briones, 1959a, pp. 24-26 y Aichinger, 2012.

${ }^{17}$ Calderón, La gran Cenobia, pp. 3-4.

${ }^{18}$ Calderón, La cisma de Inglaterra, p. 558. 
de siete cuellos, que la quarta esfera empaña con su aliento; en fin, todo su horror y su tormento en mi pecho se encierra; que yo mismo a mí mismo me hago guerra, cuando en brazos del sueño vivo cadáver soy, porque él es dueño de mi vida; de suerte, que vi un pálido amago de la muerte ${ }^{19}$.

La visión puede producir una escisión del personaje, presentándole un doble de sí mismo que le horroriza: "Que yo mismo a mí mismo me hago guerra» ${ }^{20}$. La visión asimismo produce un impulso de huida, de escapar de la propia imagen: "Escondedme de mí mismo»" ${ }^{21}$ dice Ludovico Ennio, gran pecador de la misma obra, El purgatorio de San Patricio.Y Polonia, protagonista femenina se percibe como «enemiga de mí misma» $»^{22}$. El sueño asimismo conecta la mente humana con otra esfera del tiempo:
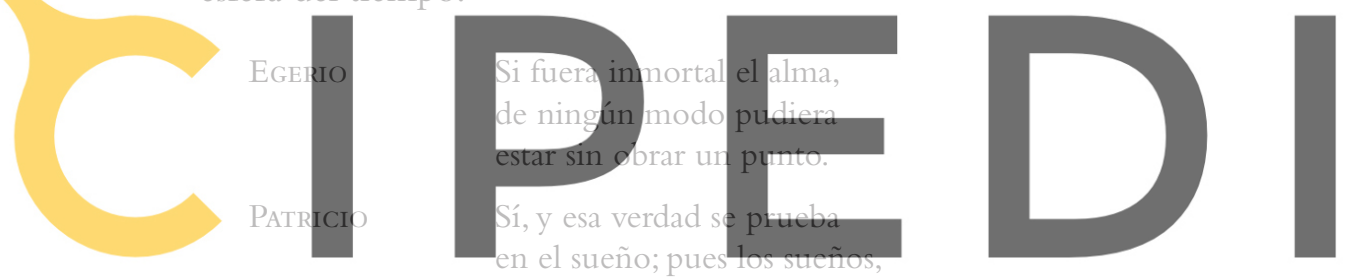

cuantas figuras engendran,

free at https//www.scipedialicomps to adow hiload the version without the wa que no duerme, y como quedan

entonces de los sentidos

las acciones imperfetas, imperfectamente forman

los discursos; y por esta razón sueña el hombre cosas, que entre sí no se conciertan.

${ }^{19}$ Calderón, El purgatorio de San Patricio, p. 269.

${ }^{20}$ Calderón, El purgatorio de San Patricio, p. 269.

${ }^{21}$ Calderón, El purgatorio de San Patricio, p. 339.

22 Calderón, El purgatorio de San Patricio, p. 319. 
Trescientos años más tarde Sigmund Freud insistirá en el hecho de que los procesos inconscientes son «zeitlos» (atemporales) ${ }^{23}$.

El vidente que entra en la noche, la cueva, la oscuridad, aguantando el «espantoso espectáculo», la «horrible visión», el «mortal asombro»" que consigue volver a la superficie, despertando de un «abismo», un «paroxismo», un «letargo» ${ }^{25}$ y además: consigue poner en palabras lo que ha visto, curará. Tal es el caso del pecador Ludovico Ennio y el mismo Calderón emplea la metáfora médica: «Médicos doctos / a peligrosas heridas / dan remedios peligrosos»" ${ }^{26}$. El sueño no solo es «maestro», tal como sucede al final de La vida es sueño, incluso puede tener valor terapéutico.

\section{El Pensamiento Vestido DE LOCO}

No podemos dar por supuesto que la producción de imágenes en la mente de una figura de comedia refleje el proceso creativo del autor. Sin embargo, algunas obsesiones de Calderón me parecen tan evidentes que podrían permitir hipótesis acerca de ecos autobiográficos. Por algo será qu el nombre del poeta está eternamente asociado al título de una comedia que como ninguna otra obra literaria explora las facultades humanus de imaginar y de soñar.

No es este el lugar para estudia:
de las cuales surgió la inspiración p

las esferas de la mente calderoriana
ra sus obras, su preferencia por ciertas materias, sus inclinaciones a la hora de escoger una imagen, una pa-

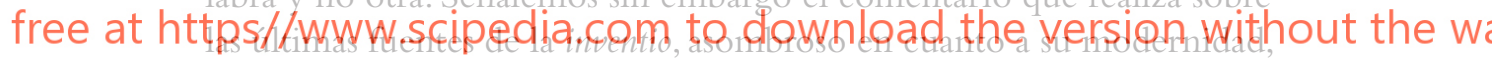

profundidad y penetración psicológica. Lo pronuncia el Pensamiento, que sale "vestido de loco" en el auto El día mayor de los días. Acude este Pensamiento al llamamiento del Humano Ingenio que busca inspiración para la obra que debe componer. Traban un coloquio que dice así:

Pensamiento

¿Qué tristeza,

humano Ingenio del Hombre,

en tu estudiosa tarea

te tiene tan suspendido?

${ }^{23}$ Freud, 1923, pp. 35-36.

${ }^{24}$ Calderón, El purgatorio de San Patricio, p. 338.

${ }^{25}$ Calderón, El purgatorio de San Patricio, p. 270.

${ }^{26}$ Calderón, El purgatorio de San Patricio, p. 341. 


\begin{tabular}{|c|c|}
\hline INGENIO & $\begin{array}{l}\text { ¡Oh, a qué mal tiempo que llegas, } \\
\text { Pensamiento, a divertirme! }\end{array}$ \\
\hline Pensamiento & $\begin{array}{l}\text { ¿Cuándo aguardo yo a que sea } \\
\text { tiempo de ir y de venir? } \\
\text { ¿Ni de cuándo acá de nuevas } \\
\text { se hace el Ingenio de que } \\
\text { con tiempo o sin tiempo venga? }\end{array}$ \\
\hline INGENIO & $\begin{array}{l}\text { Ya sé que eres loco y no } \\
\text { loco de atar, pues no hay cuerda } \\
\text { imaginación que tú } \\
\text { no rompas. }\end{array}$ \\
\hline Pensamiento & $\begin{array}{l}\text { Pues ya que es fuerza } \\
\text { que por loco tolerado } \\
\text { me sufras, dame licencia } \\
\text { de decirte que no pienses } \\
\text { penetrar eso que piensas }{ }^{27} \text {. }\end{array}$ \\
\hline
\end{tabular}

El secreto de los secretos se halla oculto en los fondos del alma, desde donde surge la inspiración del poeta. Hace falta transponerlo a las cláusulas sonoras del verso y encarnarlo sobre las tablas para que se convierta en secreto a voces.

¿Los graciosos de comedia hablan del acto de la escritura? Lo hacen cuando comentan a alguien que, atormentado por los afectos de una pasión, parece estar escribiendo una comedia. Lo mencionamos arriba. También son conscientes de que todo acto de escribir está empapado de fuertes afectos y que el tono emocional de una obra incluso puede determinar la selección, la consistencia y el color de la tinta:

$\begin{array}{ll}\text { Cosme } & \text { por un hora, que fuera } \\ & \text { antes Píramo a la fuente, } \\ & \text { no hallaba a su Tisbe muerta; } \\ & \text { y las moras no mancharan; } \\ & \text { porque dicen los poetas } \\ & \text { que con arrope de moras } \\ & \text { se escribió aquella tragedia } \\ & \end{array}$

${ }^{27}$ Calderón, El día mayor de los días, p. 75.

${ }^{28}$ Calderón, La dama duende, p. 451. 
«El lenguaje es el punto en donde se articula el consciente y el inconsciente»" . En el acto creativo Calderón libra ese "duelo mortal, antinomia de su vida, [...] entre realidad e imaginación ${ }^{30}$, entre una imaginación que no admite límites y la voluntad artística que lucha por convertirla en letra y verso encauzándola en formas literarias establecidas.

${ }^{29}$ Ricoeur, 1970, p. 11.

${ }^{30}$ Valbuena Briones, 1959b, p. 1128. 


\section{BiBLIOGRAFÍA}

Aichinger, Wolfram, «Imagen, imagen soñada y romance en Calderón», Iberoromania, 75-76, 2012, pp. 121-141.

De Armas, Frederick A., The Return of Astraea. An Astral-Imperial Myth in Calderón, Lexington, Kentucky, The University Press of Kentucky, 2014.

Calderón de la Barca, Pedro, Casa con dos puertas mala es de guardar, en Comedias, I, ed. Luis Iglesias Feijoo, Madrid, Castro, 2006.

Calderón de la Barca, Pedro, La cisma de Inglaterra, en Obras completas. Dramas, ed. Ángel Valbuena Briones, Madrid, Aguilar, 1959.

Calderón de la Barca, Pedro, La dama duende, en Primera parte de comedias de don Pedro Calderón de la Barca, ed. Ángel Valbuena Briones, Madrid, CSIC, 1974.

Calderón de la Barca, Pedro, El día mayor de los días, ed. Ignacio Arellano y Miguel Zugasti, Kassel, Reichenberger, 2004.

Calderón de la Barca, Pedro, La estatua de Prometeo, ed. Margaret R. Greer, Kassel, Reichenberger, 1986.

Calderón de la Barca, Pedro, La gran Cenobia, en Primera parte de comedias de don Pedro Calderón de la Barca, ed. Ángel Valbuena Briones, Madrid, CSIC, 1974.

Calderón de la Barca, Pedro, Nadie fíe su secreto en Obras completas. Comedias, ed. Ángel Valbuena Briones, Madrid, Aguilar, 1973.

Calderón de la BArCa, Pedro, Nadie fíe su secreto, en Comedias. Novena parte de comedias [Vera Tassis 1691], ed. facsímil Don W. Cruickshank y John E.Varey, Westmead, Gregg International Publishers, 1973.

Calderón de la Barca, Pedro, No siempre lo peor es cierto, en Obras completas. Comedias, ed. Ángel Valbuena Briones, Madrid, Aguilar, 1973.

Calderón de la Barca, Pedro, Para vencer amor, querer vencerle, en Obras completas. Comedias, ed. Ángel Valbuena Briones, Madrid, Aguilar, 1973.

Calderón de la Barca, Pedro, Prólogo que don Pedro Calderón hizo cuando imprimió el primer tomo de sus autos, en Obras completas. Autos sacramentales, ed. Ángel Valbuena Prat, Madrid, Aguilar, 1952.

Calderón de la Barca, Pedro, El purgatorio de San Patricio, en Primera parte de comedias de don Pedro Calderón de la Barca, ed. Ángel Valbuena Briones, Madrid, CSIC, 1974.

EgIDO, Aurora, «Introducción», en Pedro Calderón de la Barca, La fiera, el rayo y la piedra, ed. Aurora Egido, Madrid, Cátedra, 1989, pp. 9-127.

Freud, Sigmund, Jenseits des Lustprinzips, Leipzig / Wien / Zürich, 1923, pp. 35-36.

Greer, Margaret R., "General Introduction», en Pedro Calderón de la Barca, La estatua de Prometeo, ed. Margaret R. Greer, Kassel, Reichenberger, 1986, pp. 1-234. 
Iglesias Feijoo, Luis y Alicia Vara López, «De luces, sombras y asombros», Anuario Calderoniano, vol. extra 1, 2013 (coord. Alejandra Ulla Lorenzo), pp. 213-233.

López López Pielow, Fátima, Metamorfosis y metáfora. Mito y discurso en Pedro Calderón de la Barca y Ovidio, Berlin, Walter Frey, 2010.

Ricoeur, Paul, Freud. Una interpretación de la cultura, México, Siglo XXI, 1970.

Tirso de Molina, Quien habló, pagó, en Obras completas, IV. Segunda parte de las comedias, Madrid, Castro, 2005.

Valbuena Briones, Ángel, «Prólogo», en Pedro Calderón de la Barca, Obras completas. Dramas, ed. Ángel Valbuena Briones, Madrid, Aguilar, 1959a, pp. 9-34.

Valbuena Briones, Ángel, «Nota preliminar a Los hijos de la fortuna», en Pedro Calderón de la Barca, Obras completas. Dramas, ed. Ángel Valbuena Briones, Madrid, Aguilar, 1959b, pp. 1127-1130.

VARA López, Alicia, «El fuego en cárceles de nieve: del secreto amoroso en la comedia calderoniana», Hipogrifo, 2.1, 2014, pp. 73-85.

WARdropper, Bruce W., "La imaginación en el metateatro calderoniano», Asociación Internacional de Hispanistas, Actas III, 1968, pp. 923-930. 